\title{
LA EVOLUCION DEL CONCEJO ABIERTO Y SU RECONOCIMIENTO CONSTITUCIONAL
}

\author{
POR \\ EnRiQue Orduña Rebollo
}

SUMARIO: I. Introducción.-II. El Concejo Abierto en la Edad Moderna.-III. La ocultación del Concejo Abierto en el siglo XIX y su reaparición en el XX: a) la Constitución de 1812 ; b) la recuperación del Concejo Abierto por los regeneracionistas; c) los proyectos de Maura y el Estatuto Municipal; d) el Concejo Abierto en la legislación republicana.-IV. El Concejo Abierto desde la instauración del sistema democrático: a) proceso constituyente; b) los proyectos de Ley de régimen local; c) la Ley $7 / 1985$.

\section{INTRODUCCION}

En los últimos años, ha vuelto a sonar con insistencia creciente, como remedio a ciertos problemas que acucian a la vida local el nombre de una añeja institución municipalista: El Concejo Abierto.

Es ciertamente el Concejo Abierto la forma más antigua de organización del Municipio, en las tierras de Castilla y de León, allá por los lejanos albores de la Edad Media. Pero lo significativo es que pese a los siglos transcurridos, a los cambios sociales y a todas las reformas, la institución del Concejo Abierto pervive y goza de buena salud, condicionada su existencia a la del pequeño municipio rural y pasmémonos: en las células más pequeñas del Municipio Urbano, por debajo de los Distritos, se perfila la aparición de una fórmula próxima al Concejo o al Cabildo Abierto.

Ante ello nos preguntaremos todos con cierto asombro ¿cómo es posible que una institución surgida del "concillium» vecinal en los siglos $\mathrm{x}$ y $\mathrm{XI}$ pueda transmitirse a lo largo de los años y llegar a nuestros días con el mismo vigor? La respuesta es enormemente sencilla:

Nos encontramos ante la manifestación más viva de democracia directa en su forma más pura.

Y esa será la causa de que al intentar en nuestros días realizar un análisis o estudio global del concepto participativo del ciudadano en la Administración sea obligado incidir y conocimiento la figura del Cabildo Abierto, tanto en su esencia como en su funcionamiento (1).

Hemos indicado que el Sistema de Concejo Abierto se inició y practicó en Castilla y León a partir de los siglos X y XI. Tal afirmación no es rotunda y excluyente pues igualmente existió y existe en el

(1) Véase Valdeón Baruque, V.: «El Origen del Concejo Abierto», en El Concejo Abierto. Madrid. IEAL. 1987, pp. 1-12. 
Pirineo, en Teruel, en algunos cantones suizos, parroquias portuguesas, inglesas o suecas o comunas rurales de Austria y Alemania. Para más detalle la Constitución Alemana de Bonn de 1948 reconoce las Asambleas de vecinos, en su artículo 28 , dice «En los municipios el Ayuntamiento electivo podrá ser sustituido por el Concejo Abierto (2) (Gemeindeversammlung).

En diversas ocasiones se ha afirmado que era una institución de zonas aisladas y de alta montaña. Tampoco es real: en Castila y León existen no solo en las cordilleras que bordean la región, sino en las llanuras que compone el 80 por 100 de su territorio.

En lo que sí estamos de acuerdo es que se trata, al menos hasta ahora, de una institución natural como comunidad de vecinos en círculos preferentemente aldeanos (3).

\section{EL CONCEJO ABIERTO EN LA EDAD MODERNA}

Refugiado, el Concejo Abierto, como decíamos, en las aldeas y en los medios rurales, tal institución verá transcurrir los años y perdurará no solo en la memoria, sino en los textos, amén de las actuaciones que tenian lugar en múltiples lugares de España. Sin ir más lejos, en la provincia de Burgos, se practicaba el Concejo Abierto durante los siglos XVI, XVII y XVIII. Ha quedado constancia de ello en las Ordenanzas de Toba de Valdivieso, publicadas hace unos años (4).

Las primitivas Ordenanzas son del día 28 de mayo de 1559 , en que «estando juntos llamados por voz de campana tañida el Concejo, Rexidores, Escuderos, Hijos de Algo, e vecinos e moradores de dicho lugan», y continúa designando el sitio físico de reunión: «... donde dicen la Fuente, sitio y término acostumbran junttar el dicho Concejo...» (5).

Las Ordenanzas constituyen un texto de lectura deliciosa a lo lago de los 51 capítulos que regulan la vida y el gobierno del pueblo. Nosotros subrayaríamos para el tema que nos ocupa los capítulos $2 .^{\circ}$ a $4 .^{\circ}$, en los que se determina la obligación de todos los vecinos de asistir al Concejo cuando el Regidor las llamara de palabra o por

(2) Véase Azcárate, G.: «Municipalismo y Regionalismo». Madrid, 1978, IEAL, p. 37, lo afirmaba justo un siglo antes: «En 1877 la verdad es que fuera de España han desaparecido tales vestigios excepto en el Cantón suizo de Glagris y los cuatro semicantones Unterwalden y Appenzell opinión que nos gustaría constatar en cuanto a la pervivencia centroeuropea de tal institución.»

(3) Véase Díez González, F. A.: «El Concejo Abierto y la Ordenanza Concejil». Madrid. Caj. número 8 abril 1985, pp. 578. Funcionamiento de los Municipios y Entidades de Concejo Abierto.

(4) Véase Ballesteros, F.: «Ordenanzas del Concejo, e Inventario de documentos, de Taba de Valdivieso (Burgos)» Bolètín dé Institución Fernán Gonzáléz número 183, 1974, pp. 323-354. (En: Concejo Abierto). Madrid. IEAL. 1987, pp. 93-112.

(5) Idem, p. 328. 
campana prohibiendo las palabras injuriosas y portar armas; el quebrantamiento de alguno de estos capitulos llevaba consigo la correspondiente sanción económica.

En 1697 se incorporó un nuevo capítulo, siendo aprobadas en 1698. Constituiría el Capítulo designado como $1 .^{\circ}$ a) bajo la rúbrica «Trata de las elecciones», y en él se determinaria que la elección de dos Regidores, un Jurado y dos Apreciadores se hacian por todos los vecinos en 26 de diciembre de cada año. La Ordenanza se aprobó por «todos ellos juntos en este Concejo...» «se pidieron a el Señor Alcalde Maior mande confirmar e aprovar esta dicha Ordenanza». Se referian a la aprobación del Alcalde Mayor de las Verindades de Castilla la Vieja, el cual las habia aprobado por primera vez en 1579.

Las adiciones posteriores, organizadas en 12 nuevos capítulos, todos del siglo XviII, contiene la figura del Concejo Abierto como forma habitual de gobierno municipal. Importante es el LXIII que "Trata de los electores», aprobado el día 15 de enero de 1752, cuando «se junto el Concexo a son de campana tañida, como lo tiene de uso y costumbre de se juntar...» y en el que el acuerdo de modificar el procedimiento de elección de los regidores, fue «combenido por todos los vecino» (6).

El licenciado Jerónimo Castillo de Bovadilla, autor de la obra Política de Corregidores, importantísimo tratado de derecho público español, afirmaba en 1597:

... que en la congregación y universidad de todo el pueblo (que se llama concejo abierto) residía la mayoría y superioridad, pero ya por costumbre reside en los Ayuntamientos y consejos, los cuales solos pueden lo que el pueblo junto: pero los pueblos nombran por cuadrillas, o según sus usos y costumbres procuradores generales o sindicos, o cuatro de la ciudad y de la tierra, que asistan en los Regidores, para ver, y contradezir y apelar de lo que mal ordenaren los Regidores (7).

Como podemos ver, se reconoce al Concejo Abierto como la institución donde residía la mayoria y superioridad, aunque ya para aquella época, fines del siglo XVI, principios del XVII por la fuerza del hábito se encuentra residenciadas en los Ayuntamientos ambas cualidades, pero el Concejo Abierto seguía existiendo, en las zonas rurales como más adelante lo reconoce:

«... que los Regidores representan al pueblo; y todos los estados de la República, y tienen el poder della para todas las

(6) Idem, p. 345.

(7) Véase CAstillo de Bovadilla, J.: «Política para Corregidores y Señores de Vasallos». Amberes. 1704. Vol II, pp. 121 y 122. 
cosas que le tocan y convienen, sin que sea necesario concejo abierto para ello: esto es en las pequeñas villas constumbre y de juntarse el pueblo para algunas cosas señaladas; y en el Corregimiento de Vizcaya, de que es cabeza la villa de Bilbao, se junta y congrega para algunas ocasiones en el campo do dizen el arbol de Guernica» (8).

Cualquier comentario sobra, pero debemos indicar que no es del todo cierto que no se celebrasen Concejos Abiertos en diversas ciudades, avanzados los siglos XVI y XVII, fundamentalmente porque no existió nunca prohibición escrita de realizarlo. Ahora bien esta manifestación de democracia directa de carácter local ¿ponia en realidad dificultades a los gobernantes del llamado siglo de oro? Nuestra respuesta es afirmativa en el caso de las aldeas y pueblos. pero es más dubitativa en cuanto a las ciudades, donde es probable que en ocasiones diesen asentimiento y audiencia popular a unos acuerdos tomados por la oligarquía municipal que era depositaria de los enajenados oficios concejiles.

La prueba de que se celebraban Concejos Abiertos la tenemos en los celebrados en Calahorra en 1616 y en 1645 (9) en Aranda de Duero en 1650 (10) en Logroño en 1595 y en Alfaro en 1602 (11)

Este caso ha sido afortunadamente investigado con todo rigor por el historiador I. A. A. Thompson, al haber encontrado en el Archivo General de Simancas un legajo que contenía toda la información al respecto, en el que además de poder conocer todo el procedimiento seguido en el desarrollo del Concejo Abierto, se trata de un asunto que realmente cuestionaba el status oligárquico, ni más ni menos se discutía la continuidad o no del sistema de regimiento perpetuo en Alfaro (12).

El asunto en sintesis era el siguiente:

En Alfaro hasta 1543 su Concejo estuvo gobernado por regidores elegidos cada año. A partir de esa fecha comienza la venta de oficios permanentes y en 1602 la estructura del Cabildo era la siguiente: la justicia real, el alcalde mayor, un alférez mayor perpetuo, un depositario general por dos vidas, 18 oficios de regidores de por vida y 12 diputados anuales, seis hijosdalgo y seis de los labradores. Ninguno parecía que era muy eficaz ya que la propuesta realizada era la de consumir todos los oficios, tanto los perpetuos como los anuales.

(8) Idem, p. 127.

(9) Véase Gutierrez y Acutegui, P.: en Historia de la Muy Noble, Antigua y Leal Ciudad de Calahorra. Logroño. Berceo. 1957, 473: 1958, p. 82.

(10) Véase Sanz Abad, P.: Historia de Aranda de Duero. Aranda, 1975, p. 226.

(11) Véase Thompson, I. A. A.: «El Concejo Abierto en Alfaro en 1602: La lucha por la democracia municipal en la Castilla seiscientistas. Logroño. Cuadernos de Investigación número 3. 1984 , pp. $307-331$.

(12) Véase A. G. S.: Cámara de Castilla. Serie XII Oficios, legajo 1 (agregada). 
En consecuencia el síndico general de Alfaro en 1602 dirigió el Rey una instancia en nombre de todos los vecinos, suplicándole que mandase consumir los oficios de regidores, alférez y depositario, y los convirtiese en electivos y anuales tras la celebración del correspondiente concejo abierto. El 7 de abril del mismo año el secretario del Consejo de Hacienda expidió una cédula real autorizando la celebración del Concejo Abierto y encomendando su cumplimiento al Corregidor de Agreda.

Las órdenes recibidas consistían en reunir a todos los vecinos y moradores que lo deseasen, un día de fiesta tras el toque de campana, y conocer su decisión sobre el problema. Excluía de la asistencia del Concejo a toda la junta de regidores y sus parientes y allegados. Fue delegada la comisión en el regidor perpetuo de Agreda, Marcos de Harobio, el cual se personó en Alfaro, dictando tres autos:

$1 .^{\circ}$ Ordenó el pregón convocando a todos los vecinos en la Iglesia de San Miguel de Avila, a la una de la tarde, para dilucidar sobre los asuntos de la cédula real.

2. ${ }^{\circ}$ Prohibió la asistencia de los afectados regidores bajo multa de 50.000 maravedies para la Cámara del Rey.

3. Prohibió las coacciones en la asistencia y la expresión libre, asi como escándalos, tumultos, etc., con la misma sanción.

Tras diversos incidentes y querellas sobre este último punto, con algún detenido, el pregonero tañió la campana durante largo rato y se juntaron en la iglesia 274 personas (13).

Tras la lectura de la real cédula los asistentes deliberaron sobre el problema y sus consecuencias, ya que la cédula real disponía que al eliminar las fuentes de ingresos por la venta de oficios, los ciudadanos debian realizar la compensación económica que ascendía a 25.000 ducados. El parecer general fue de que se quitasen los regimientos perpetuos por los grandes perjuicios que ocasionaba, opinando en este sentido 268 de los asistentes. Tras diversas gestiones y diligencias, se consiguió por los ciudadanos de Alfaro eliminar el regimiento perpetuo y la venta de oficios, tras el correspondiente mandato real (14).

Hay otras noticias de celebración de Concejos Abiertos en lugares y pueblos de Castilla y León a lo largo del siglo xvir, por ejemplo el caso de Rueda, que el 21 de mayo de 1636 obtuvo la exención y el privilegio de villazgo cesando en su dependencia jurisdiccional de Medina del Campo, tras la unánime opinión de una gran mayoria de

(13) En el Censo de 1591 Alfaro contaba con 1.207 cabezas de familia.

(14) Véase Thompson, I. A. A.: El Concejo... hemos seguido puntualmente su relato sintetizado por razones obvias, pero su interés y confirmación de algunos aspectos de nuestro trabajo así lo requeria; por lo demás la lectura del trabajo de Thompson es obligada para cualquier estudio del municipio español en la Edad Moderna. 
sus vecinos, expresada en un Concejo Abierto, convocado con tal fin (15).

Aunque consta la existencia de más casos, es preciso señalar la ausencia de estudios concretos, quizá investigaciones posteriores más profundas, como la de Thompson, nos den una panorámica amplia del problema, al cual los dos Repertorios usuales: La Nueva Recopilación o la Novisima, no hacen referencia en contra, aunque si recogen las leyes que protegen usos y costumbres. Por ejemplo la Ley dictada por don Alfonso XI en Valladolid en 1343 disponiendo «que a las ciudades y villas se les guarden sus privilegios, oficios y libertades y buenos usos y costumbres» (16) o todo el título IV, del libro VII de la Novísima «De los privilegios y costumbres de lo pueblos para la elección de oficios» (17). Constantemente se hacen referencias a la obligatoriedad de mantener y realizar los diversos asuntos según el «uso y buenas costumbres de los pueblos".

Hacia 1740, Lorenzo de Santayana Bustillo, natural de Salamanca, fiscal de la Audiencia Real de Valencia y en aquel momento Oidor de la Real Academia de Zaragoza escribe un libro que se publicará dos años después, bajo el título de: «Gobierno político de los pueblos de España, el Corregidor, alcalde y juez de ellas» (18).

Siglo y medio más tarde de la monumental obra de Castillo de Bobadilla, este magistrado salmantino, arraigado en la Corona de Aragón, trata de resumir y corregir al medinense Castillo, haciendo una obra más reducida y más práctica y útil para los funcionarios y oficiales reales.

En el capítulo III de su libro titulado De la celebración de los Ayuntamientos y Concejos, ya particulares, ya generales nos da diversas noticias del funcionamiento y existencia de la Institución.

Textualmente dirá:

«Dos especies de Ayuntamientos o Concejos se practican hoy en día en los pueblos, uno de los que se dicen particulares; otras de los generales que se llaman abiertos» (19).

Los abiertos o generales se realizaban habitualmente en los lugares pequeños, y en ellos, fundamentalmente, se elegian los «sirvientes del

(15) Véase Martínez Llorente, F. J.: Rueda: de aldea a villa..., en prensa. Lo cita González Díaz, E.: «La Desmembración de la Tierra de Medina. Señorios y Villazgos». (En: Historia de Medina del Campo y su Tierra). Valladolid, 1986. Vol. I, p. 755.

(16) Vèase Nueva Recopilación: (Ed. facsimil. Valladolid 1982). Vol. II, fol. 200 vto. En novisima Recopilación (Ed. facsimil. Madrid, 1973). Vol. III, p 287.

(17) Véase Novisima ..., pp. 287-294.

(18) Véase Tomás y Valiente, F.: Estudio preliminar a la obra «Gobierno político...», Madrid. IEAL. 1979, p. XI.

(19) Véase: Santayana y Bustillo, L.: Gobiernó politico de los pueblos de España. Madrid, «Ideal», 1979, p. 27. 
pueblo»; médico, cirujano, boticario, herrador, albéitar, maestro de escuela, de gramática, etc., igualmente se realizaban Concejos Abiertos para tratar asuntos que afectasen a los intereses comunes de todos los vecinos, como repartimientos o contribuciones.

También indica Santayana la costumbre en «poblaciones cortas» de hacer Concejos particulares para la elección de oficios subalternos del propio Concejo, como escribano, fiel de hechos, contador, administrador de propios, guardas de montes y huertas y, en general, «para todo lo que concierne a la recaudación de rentas y bienes del común y demás obligaciones propias de los regidores y síndico por razón de sus oficios» (20).

Gran importancia tenía el Concejo Abierto en las Ordenanzas de los pueblos, pues, como es sabido, el hacerlas era una facultad que tenían los pueblos. Esta importancia es también notoria en la administración del patrimonio del pueblo o propios, pues las obligaciones que se adquirían en tal sentido por los regidores no eran potestad de los Concejos particulares, sino que «era necesario que el poder o mandato tuviese inserta la cláusula é de si todo el Concello» (21).

Respecto a la periodicidad prevista para la celebración del Concejo Abierto, éste tenía lugar cuando existía un motivo o asunto concreto para tratar y discutir, excepto las fechas fijas en que se elegían los oficios. En cuanto a la citación, ésta tenía que ser a toque de campana, por pregón o anuncio, pero en los acuerdos y asuntos importantes y en las elecciones de oficio la citación había de ser personal y a todos los vecinos.

Quizá la diferenciación que hace Santayana entre Concejo general y particular pueda inducir a error por la composición del mismo. Interpretamos que la división se hace en función de los asuntos, no del número de participantes o de una posible representatividad. Los miembros del Concejo Abierto, tanto en un caso como en otro, eran todos los vecinos del pueblo.

El gobierno, presidencia y autoridad del Concejo recaía en el Alcalde, el cual, al igual que en los municipios regidos por Ayuntamientos, tenia las facultades de hacer guardar el respeto, no portar armas, cuidar de la libertad y autonomía del Concejo, de la ejecución de sus acuerdos, etc.

En la obra de Santayana se describen otros múltiples aspectos de cómo se desarrollaba el funcionamiento de la vida municipal, aunque en múltiples ocasiones existia un claro solapamiento entre los municipios que funcionaban en régimen de Ayuntamiento sobre los de Concejo Abierto, aunque claramente se deduce de su lectura que

(20) Ibidem: pp. 27 y 28.

(21) Ibidem: p. 87. 
prácticamente todos los aspectos del Concejo Abierto, tanto los de organización como de funcionamiento, se encontraban perfectamente regulados, incluso en los detalles, y que con carácter suplementario se recurría a la normativa prevista para los Ayuntamientos cuando se carecía de legislación al respecto.

\section{LA OCULTACION DEL CONCEJO ABIERTO EN EL SIGLO XIX Y SU REAPARICION EN EL XX}

\section{a) La Constitución de 1812.}

La Constitución de 1812 va a suponer la incorporación de España al concepto moderno de los postulados democráticos, unitarios y liberales. Aunque tal incorporación no sea un hecho permanente y firme hasta 1833.

El proceso de elaboración de la Constitución gaditana va a suponer un estudio profundo de todo el proceso foralista español, tanto en los niveles regionales como en los municipales, así como en la historia medieval de éstos, según se manifestaría ampliamente en los debates. Pero, sin embargo, la figura del Concejo Abierto va a ser ignorada, pese a la ambigua redacción al respecto del artículo 310 (22). Igualmente el artículo 313 determinará que todos los años, en diciembre, «se reunirán los habitantes de cada pueblo para elegir a pluralidad de votos...», en definitiva, articulaba un procedimiento indirecto para elegir los cargos, que desde entonces dejan de ser oficios perpetuos, pero nada más. Algunos autores dirán que tales artículos implicitaban el reconocimiento del Concejo Abierto. Nosotros no somos tan optimistas. No lo derogaban por imposibilidad material, pero tampoco le prestaban reconocimiento formal, relegándole al olvido.

Tampoco aclaraba mucho en este sentido el discurso preliminar del proyecto de Constitución, pues uno de sus párrafos decía:

«No entrará tampoco (la Comisión) en el origen de las Comunidades o asociaciones libres de mucha parte de Europa que establecieron en la Edad Media... el gobierno municipal de muchas ciudades bajo forma popular. Lo que sí es indudable es que en España se siguió la misma costumbre según iba progresando la restauración. Los Ayuntamientos de las ciudades y pueblos de los diferentes reinos de la Península... estaban fundados en el justo principio del interés de la

(22) Dice el referido artículo: «Se pondrá Ayuntamiento en los pueblos que no lo tengan y en que convenga le haya, no pudiendo dejar de haber en los que por si o con su comarca lleguen a mil almas y también se les señale término correspondienten. 
Comunidad. Pero el espíritu señorial que dominaba en todas las instituciones de aquella época destruia la naturaleza de unos establecimientos que deben reposar únicamente sobre la confianza de los pueblos en los individuos a quienes encomienda la dirección de sus negocios.»

Ambiguo texto, nuevamente, en lo que se refiere al Concejo Abierto, donde además se detecta un error histórico al hacer coincidir el régimen señorial con la aparición del municipio, después los señoríos. Pero, en descargo de los doceañistas, diremos que su rechazo a los sistemas señoriales era radical, asi como todo lo que supusiera privilegio. El remedio para frenarlo: la generalización de Ayuntamientos en todo el territorio español.

Tal situación de ignorancia del Concejo Abierto se sucederá en las Constituciones del siglo XIX y en la legislación municipal emanada de ellas. Pero el Concejo Abierto seguirá funcionando relegado en aldeas y pueblos, a pesar de todas las vicisitudes.

Sin embargo, esta ignorancia legal va a ser obviada por el trabajo científico que a partir de 1850 iniciará una recuperación de los aspectos históricos del municipio español. Citaremos a Muñoz y Romero, Colmeiro, Sacristán hasta Joaquín Costa, que en sus «Materiales para el estudio del derecho municipal consuetudinario en España», publicado en 1877, hará un minucioso estudio de todos los lugares de España donde se realizaba el Concejo Abierto.

Quizá tal corriente inspirase el proyecto de Ley de 1884 elaborado por Romero Robledo, que, anticipándose a los proyectos de Maura de 1907, reconocía la tipología y diversidad municipal, intentando generalizar el Concejo Abierto entre los pueblos de menos de 500 habitantes, más de la mitad de los existentes en España, e igualmente proponía la implantación del Concejo Abierto restringido en los pueblos que tuviesen 500 y 1.000 habitantes, aunque tanto en un caso como en otro con la restricción de que sólo podrian participar en el Concejo los vecinos que reuniesen las condiciones exigidas en la Ley electoral para ser electores de diputados a Cortes, o sea un sistema censitario que sólo permitía participar a las personas principales y a los mayores contribuyentes de la localidad (23), lo que, de haberse convertido en Ley, hubiese limitado notablemente las posibilidades de participación y asistencia. ¡Y tal situación se producía tras la Restauración canovista!

(23) Véase: Ley Electoral, 1878, art. 15, que preveía el pago de 50 pesetas de contribución durante los dos últimos años o 25 pesetas anuales de territorial, para poder ser elector. 
b) La recuperación del Concejo Abierto por los regeneracionistas.

A fines del siglo XIX y principios del $\mathrm{XX}$ se produjo el movimiento regeneracionista, tras la liquidación de los últimos vestigios del imperio colonial. Como es sabido, surgirá una fuerte corriente intelectual, reformista y regeneracionista que a nuestros efectos va a resultar importantísima al tratar de erradicar el caciquismo de la vida pública local y restaurar la democracia en todos sus extremos sin manipulaciones, adulteraciones y sin elecciones amañadas desde el Ministerio de la Gobernación, que desvirtuaban completamente el panorama político español.

Aunque ya hemos hecho referencia al papel de Joaquín Costa al mencionar sus trabajos de Derecho Consuetudinario, va a ser en este contexto regeneracionista donde haga su propuesta renovadora por medio del mensaje y programa de la Cámara Agrícola del Alto Aragón de 13 de noviembre de 1898. En el capítulo de «Regiones y Municipios» proponía para los lugares de «corto vecindario» el Concejo o Junta de vecinos como expresión de democracia directa sin Ayuntamiento y no dependientes de otro, siguiendo la costumbre que se había mantenido hasta entonces en gran parte de España (24).

En tales circunstancias, el Concejo Abierto gozaba de todos los auspicios favorables cualidad de ostentar un sistema de democracia natural y directa en el mayor estado de pureza; por otro, un importante y selecto grupo de juristas, que serán los que den verdadera carta de naturaleza moderna al Concejo Abierto. Entre estos, los más significativos serán: Costa, Azcárate, Hinojosa y Posada.

A ellos debemos, principalmente, el que la institución regida por la costumbre, después recogida en fueros y ordenanzas municipales y olvidada en los proyectos y textos legales del siglo XIX cuando se iniciaba el municipio constitucional, fuese incorporado a los más importantes textos del siglo $\mathrm{xx}$, por la indudable influencia de estos ilustres maestros del derecho, los cuales, además de su erudición histórica por vinculaciones de uno u otro tipo, llegaron a presenciar e incluso participar en estas manifestaciones del Concejo Abierto (25).

c) Los proyectos de Maura y el Estatuto Municipal.

La primera ocasión será el proyecto de reforma del régimen local de 1907 elaborado por don Antonio Maura. Tras el paso del

(24) Véase Costa, JoAQuíN: «Reconstitución y europeización de España. Mensaje y programa de la Cámara Agricola del Alto Aragón», IEAL, Madrid, 1981, p. 30. Derecho Consuetudinario, Madrid, 1902, 2 vols.

(25) Véase Azcárate, Justino, y Orduña, Enrique: Estudio preliminar a la obra «Municipalismo y Regionalismo», de Gumersindo Azcárate, IEAL, Madrid, 1978, pp. XXX y XXXI. 
mencionado proyecto por la Comisión del Senado, ésta incorporó en el dictamen la distinción del Concejo Abierto entre diversas formas municipales, concretándose el artículo 38 en los siguientes términos:

«En los municipios menores de 200 habitantes serán concejales todos los electores en Concejo Abierto. En los mayores de 200, menores de 500 habitantes, serán concejales todos los electores en Concejo Abierto cuando por acuerdo de los vecinos reunidos en asamblea, y por mayoria de dos tercios, se establezca este régimen.»

Para don Adolfo Posada suponía tal artículo la resurrección y consagración del Concejo Abierto, pues «si por una parte se restaura o respeta una costumbre tradicional no enteramente perdida..., por otra parte afirma el sentido democrático en la base del régimen municipal» (26).

Sabida es la suerte que corrieron los proyectos de don Antonio Maura, pero también es conocido que su espíritu inspirará el Estatuto Municipal de Calvo Sotelo de 1924 y, en consecuencia, por primera vez en la España contemporánea se reconocerá en un texto que estuvo en vigor la existencia del Concejo Abierto, regulando su actividad y organización. Tampoco podemos olvidar el contexto autoritario en que se desenvolvió el Estatuto Municipal, pero sí por tales circunstancias en el régimen de Concejo cerrado no hubo nunca elecciones, en las de Cabildo Abierto se continuó la actividad democrática, ahora respaldado por un texto de rango primordial.

$\mathrm{Al}$ referirse al municipio rural, el preámbulo del Estatuto ya hace una afirmación de reconocimiento de la institución: «... se instaura la forma más plena de la democracia pura: el Concejo Abierto, institución de castizo sabor nacional que regirá en más del 50 por 100 de los municipios existentes, o sea, en todos los que no excedían de 1.000 habitantes.»

El texto del Estatuto determinaba en su artículo 42 que en los municipios inferiores a 500 habitantes serian concejales todos los electores en Concejo Abierto. Respecto al tramo de municipios comprendido entre los 500 y los 1.000 habitantes, preveía que serian concejales cada tres años la mitad de los electores no incapacitados para el cargo (27). Esta última forma de rotación fue objeto de suspicacias y se la definiría irónicamente como Concejo Entreabierto.

(26) Posada, Adolfo: «Evolución legislativa del Régimen Local en España», IEAL, 2. a ed., Madrid, 1982, p. 473.

(27) Téngase en cuenta que el Estatuto de Calvo Sotelo se regia por la Ley Electoral de 8 de agosto de 1907, lo que a la larga le imposibilitaria su desarrollo. No es válido establecer un paralelismo con el proyecto de Romero Robledo de 1884, porque la Ley de 1907 sólo admitia el sufragio universal directo, libre y secreto. El Estatuto en su artículo 51 determinaba que eran electores de cada municipio «los españoles mayores de veintitrés años», incluyendo a las mujeres cabeza de familia.

REVISTA DE ESTUDIOS. -4 
Punto de referencia importante será el de las Entidades locales menores, las cuales, según el artículo 105, se gobernarian «en régimen igual al del Concejo Abierto, aunque éste no sea aplicable al municipio de que formen parte. Tal asunto planteaba y plantea cierta problemática, que señalará acertadamente DíEZ GoNZÁLEZ, pues teniendo en cuenta el elevadísimo porcentaje de aldeas, no municipios, que celebran Concejo Abierto, se dará la paradoja de que no se realice un Concejo Abierto general, lo que indudablemente resultaría de gran utilidad al tratar los temas generales de gran interés para el municipio (28).

En el caso de las Entidades menores, el Concejo Abierto lo integraban todos los electores de ambos sexos, los cuales debían reunirse en asamblea dos veces al año por lo menos y, además, cuando lo acordase la Junta Vecinal.

Para los municipios menores de 500 habitantes se determinaba con carácter obligatorio el primer domingo del año económico en que correspondiese la renovación trienal para constituir la Corporación y elegir alcalde y tenientes de alcalde. En cuanto a los municipios comprendidos entre los 500 y los 1.000 habitantes, además de cumplir los requisitos para los menores de 500, se reunirían el mismo día y en la sesión examinarian la capacidad legal de los nuevos miembros del Concejo contra los que se hubiese presentado reclamación por cualquier vecino del pueblo.

Respecto al lugar de reunión del Concejo Abierto no se determinaba ninguno, pero se excluía la Casa Consistorial, prevista sólo con carácter obligatorio para las reuniones del Ayuntamiento de régimen cerrado. Igualmente quedaba regulado el régimen de sesiones, las cuales tenian que celebrarse en días festivos, siendo preciso que en la primera convocatoria se encontrasen presentes la mayoría de los vecinos $\mathrm{y}$, en segunda, podría celebrarse la sesión, «cualquiera que sea el número de los que asistan». También todos los acuerdos debian tomarse por mayoría de votos.

Detalle muy importante era el del control de los acuerdos del Concejo Abierto, los cuales, según el artículo 264, serían «recurribles en la forma y plazos establecidos para los que tomen los Ayuntamientos», o los casos enumerados en el artículo siguiente para el tipo de recursos contra los acuerdos de las Entidades locales menores.

El capítulo IV, dedicado al régimen de tutela, también hacía mención en el artículo 288 a los Concejos Abiertos, en los que se hubiesen dado las circunstancias de déficit presupuestario tres años consecutivos previstas también para los Ayuntamientos y en el que se disponia que:

(28) Véase Dịez González, F.: El Concejo..., op. cit. p. 582, el cual hace parecidas reflexiones respecto al proyecto de Régimen Local de 1982 elaborado por la UCD, que no prosperaria. 
«La Junta de Rehabilitación reemplazará a la Comisión Municipal Permanente, sustituyéndola en las funciones que esta Ley le encomienda y asumiendo, además, todas las facultades del Consejo hasta la aprobación definitiva del presupuesto de rehabilitación previamente discutido y votado por el común de los vecinos.»

El Estatuto Municipal preveía como forma de participación directa de los ciudadanos en la Administración el referéndum, el cual era obligatorio en una serie de situaciones tales como enajenaciones o gravamen de bienes, concesiones de obras o servicios por más de treinta años, etc. Sin embargo, dado el carácter totalmente participativo del Concejo Abierto, el referéndum no era preciso cuando el municipio se regía por este sistema y el acuerdo hubiese sido «adoptado por mayoría absoluta de electores en reunión extraordinaria convocada al efecto".

Creemos que en esta primera ocasión de reconocimiento legal del Concejo Abierto se articula primariamente la regulación y funcionamiento del mismo, complementada por el Reglamento de Población de 2 de julio de 1924 , cuyo artículo $2^{\circ}, b$ ), referente a la constitución de Entidades locales menores, considerará como una de las causas para ello la solicitud de «reconocimiento del Concejo Abierto de carácter tradicional». Lo que obligará al Ayuntamiento y al gobernador civil a la constitución de la Entidad local menor.

No creemos que el equipo dirigido por don José Calvo Sotelo que redactó el Estatuto Municipal (Jordana de Pozas, Gil Robles, Pí Suñer, entre otros) concibiese el Concejo Abierto como una alternativa al régimen de Ayuntamientos. Aprovecharon la circunstancia histórica y lo extendieron a todos los municipios menores de $500 / 1.000$ habitantes como fórmula más práctica a la vez que confirmatoria de una costumbre enormemente arraigada y que existía de facto (29).

En el ámbito de la legislación emanada del directorio militar, referida a régimen local, nos encontramos con el Real Decreto-ley de 4 de noviembre de 1925, aprobando las bases para la aplicación del Estatuto Municipal en la provincia de Navarra, ya que es preciso recordar que el Gobierno del general Primo de Rivera conservó el régimen económico especial del País Vasco y Navarra con sus conciertos, Diputaciones Forales, etcétera, y sabido es que en Navarra también existe desde tiempo inmemorial el Concejo Abierto.

(29) Véase García Alvarez, Manuel B.: «El Concejo Abierto en la legislación española», Revista de la Facultad de Derecho de la Universidad Complutense núm. 53, Madrid, 1978, p. 79, donde muestra algunas dudas al respecto. 
En la base segunda de este Real Decreto-ley se reconoce la existencia del Concejo Abierto para los pueblos menores de 250 habitantes, con arreglo a lo dispuesto en la Ley 60 de las Cortes de Navarra de 1817 y 1818.

\section{d) El Concejo Abierto en la legislación republicana.}

Ya hemos indicado en otros lugares las causas de frustración del Estatuto (30), pero el caso es que, al producirse el advenimiento de la II República en abril de 1931, se llevó a cabo una revisión de la legislación del periodo dictatorial, derogando una gran parte, modificando y conservando parcialmente otra. Entre las últimas se encontrará el Estatuto Municipal, cuya supervivencia no terminará aquí, pues durante muchos años aún continuarían en vigor numerosos preceptos e incluso fragmentos muy importantes de sus Reglamentos.

La Constitución republicana, promulgada en diciembre de 1931, reconocía por primera vez la autonomía plena de los Ayuntamientos, e igualmente en el mismo artículo $9 .^{\circ}$ especificaba que todos los municipios de la República elegirían «sus Ayuntamientos con sufragio universal directo y secreto, salvo cuando funcionen en régimen de Concejo Abierto».

Indudablemente, la presencia viva del Concejo Abierto había dado un gran paso, pues no se concebiría en el futuro la redacción de un texto legal democrático que afectase a la organización territorial sin reconocer la existencia del Concejo Abierto. En esta ocasión, al dársele valor constitucional, quedaría definitivamente la manifestación primaria de democracia pura en que coinciden, hasta el punto en que ello es posible, los gobernantes y los gobernados dentro del municipio (31).

Antes que la Ley municipal republicana de 1935 existe una norma regional que regulaba el Concejo Abierto, con lo que se confirma una vez más la extensión de esta figura por toda España desde lejanos tiempos. Se trata de la Ley Municipal de Cataluña de 14 de agosto de 1933, la cual introduce en su capítulo IV algunas variaciones importantes respecto al tratamiento dado por el Estatuto Municipal, ya que no hace referencia al número de habitantes para constituirse en Concejo Abierto, sino a un factor de carácter económico: tener aprovechamientos comunales, «cuyo rendimiento representa la cuarta parte o más del presupuesto municipal». Todos los vecinos elegibles tendrian categoria de consejeros municipales y en la primera sesión constituirían el Ayuntamiento, presididos por el vecino de más edad

(30) Véase Nuestro trabajo. Nota preliminar a Legislacıón de Administración Local, vol. II, páginas. XX y XXI.

(31) Véase Pérez Serrano, Nicolás: La Constitución Española (9-12-1931), Madrid, 1932, página 86. 
y eligiendo una Junta Vecinal, formada por un presidente, que sería el alcalde, y un número de vocales superior a dos e inferior a cuatro. El candidato más votado sería el alcalde. Creemos importante reproducir el artículo 39 por lo que a los aspectos organizativos se refiere:

«La Junta Vecinal administrará los intereses del común y cumplimentará los acuerdos que el Consejo general tome.

El Consejo general funcionará en la misma forma que el Ayuntamiento en pleno, previa convocatoria, según consuetud.»

Entramos a partir de aquí en la consideración y estudio de la figura del Concejo Abierto en los proyectos y en la Ley Municipal de la República, Ley que no olvidemos se presentó a las Cortes por el Gobierno radical el 1 de octubre de 1934, siendo ministro de la Gobernación don Rafael Salazar Alonso, y tres días antes de que se produjesen los tristes sucesos de Asturias y Cataluña. Aquellas circunstancias influirían y retrasarían notablemente la tramitación del proyecto $\mathrm{y}$, además, supondría la ausencia parlamentaria de una parte considerable de las fuerzas políticas, fundamentalmente Izquierda Republicana y Socialista.

El proyecto que seguía en muchos puntos literalmente al Estatuto Municipal preveia que en todos los Ayuntamientos no superiores a 500 habitantes serían concejales todos los electores en Concejo Abierto, disponiendo la existencia de un alcalde y dos tenientes de alcalde, elegidos en Concejo Abierto, entre los electores de uno u otro sexo que supiesen leer y escribir.

La base XI regulaba el Concejo Abierto atribuyéndose las mismas facultades que tuviese el Ayuntamiento y fijaba una reunión trimestral en sesión ordinaria, previamente convocada según la costumbre de la localidad.

La elección de alcalde se haría casa tres años el mismo día fijado para la constitución de los Ayuntamientos bajo la presidencia del elector de más edad.

El proyecto pasó a la Comisión de Gobernación, que emitió el dictamen en 1 de febrero de 1935, marcándose cada vez más la escasa calidad del proyecto. En el nuevo texto, el Concejo Abierto ocuparía la base XII y se ampliaría el segundo párrafo en el sentido de que el día que se constituyese el Ayuntamiento se elegirían el alcalde y uno de los tenientes de alcalde, los cuales se elegian por seis años, «renovándose uno de ellos cada tres...».

Los debates posteriores en las Cortes caerian en la más absoluta indiferencia, pero, además, los parlamentarios de más categoría de la 
derecha (Irujo, Cambó, Royo Vaillanova y el propio Calvo Sotelo) que intervenian señalaban que el Estatuto Municipal superaba al proyecto presentado en calidad técnica y grado de autonomía municipal. Cambó, líder de la Lliga catalana, en una intervención manifestó que el proyecto en materia de autonomía municipal representaba «un enorme retroceso respecto a cuantos proyectos se han formulado desde 1903 (32).

La Ley de Bases se publicó el 10 de julio, sin aprobarse las comprendidas entre los números 29 a 35 , correspondientes a las Haciendas Locales, que se aprobarian posteriormente. El Concejo Abierto no tendria modificación alguna respecto al dictamen emitido el 1 de febrero, y tras las vacaciones parlamentarias se redactó el texto articulado con algunas protestas de los diputados de Unión Republicana, la ausencia de la izquierda y la indiferencia de la derecha, con las características y peculiaridades señaladas anteriormente en cuanto a su calidad (33).

El texto articulado de la Ley Municipal apareció el 31 de octubre de 1935, siendo rectificado por errores el día 3. Según el artículo 37, el Ayuntamiento y el Concejo Abierto, en su caso, eran los órganos supremos de la Administración municipal, estando formado el Concejo Abierto, de acuerdo con el artículo 38, por todos los vecinos en su calidad de concejales, el alcalde, dos tenientes de alcalde y un síndico, figura nueva que se incorporaba respecto a la Ley de Bases y cuyas funciones eran la censura y revisión de las cuentas y presupuestos locales; el síndico se elegía entre los concejales. El sistema de elección previsto en el artículo 54 permanecía en los mismos términos. En cuanto a las sesiones, de acuerdo con el artículo 57, se incorporaban los extremos ya previstos en el Estatuto Municipal respecto a la primera y segunda convocatoria, aclarando en este caso que «serán válidos los acuerdos cualquiera que se el número de los electores que asistan, salvo los casos en que esta Ley exija requisitos especiales».

Se incluía la obligatoriedad en el artículo 65 de remitir cada trimestre al gobernador civil un estracto de los acuerdos adoptados, al objeto de su publicación en el plazo de treinta días en el Boletín Oficial de la provincia. Finalmente tampoco, como en el caso del

(32) Véase Diario de Sesiones de las Cortes núm. 160, de 15 de febrero de 1935, p. 6359.

(33) Véase nuestro trabajo: Nota preliminar a Legislación sobre Administración Local, vol. II, páginas XLIII-XLVI. Ultimamente hemos detectado con sorpresa que diversos autores atribuian a la Ley Municipal Republicana un carácter autonomista y modélico del que a todas luces carece. Así, BORJA, J.: Descentralización y participación (en Jornadas sobre perspectivas de la descentralización), Madrid, 1987, p. 68 , en que refiriéndose al referéndum como forma de participación afirma «que en España fueron regulados con gran rigor por la legislación republicana de los años treintas. Se trata, como sabemos, de una figura aparecida por primera vez en el Estatuto Municipal y reproducida fielmente por la Ley Municipal de 1935. 
Estatuto, seria de aplicación el referéndum cuando se tratase de acuerdos adoptados por mayoría absoluta, según figuraba en el artículo 97.

Unos meses más tarde comenzaria la guerra civil, y un sistema de autoridad rígidamente centralista y unitaria eliminaría cualquier atisbo de autonomía municipal. Para mayor contradicción, el régimen político salido de la victoria bélica, en la práctica, ignoraba las costumbres y las instituciones basadas en las mismas, pese a realizar profusas manifestaciones permanentes de defensa de las tradiciones.

\section{EL CONCEJO ABIERTO DESDE LA INSTAURACION DEL SISTEMA DEMOCRATICO}

Pese a todas las dificultades y contrariedades, el Concejo Abierto existió y continúa existiendo y desarrollándose en las aldeas y municipios. Esta vez sacudidas por un riesgo de extinción y abandono debido al éxodo del campo a la ciudad, pero a pesar de ello y de las amenazas de una tecnocracia que basa su acción exclusivamente en la eficacia y los rendimientos, aún existen los Concejo Abiertos con frescura y vitalidad. No son estas aldeas «polvo social» como algún municipalista ha podido destempladamente afirmar y al que DíEz GoNZÁLEZ da cumplida respuesta. Este autor, que une la experiencia en sus años jóvenes de secretario de Administración Local por los Ayuntamientos lacianiegos, en los que participó en diversas actividades del Concejo Abierto con los profundos estudios que ha realizado sobre el tema, dotados de rigor y seriedad, afirmará seguidamente que los concejos:

«Son vida y hasta raíz de vida, que se dan multiplicadamente todavía en varias de nuestras regiones; vidas que requieren vida, porque la dan, es decir, requieren reconocimiento, respeto, normas acogedoras y eficaces asistencias que no desfiguren la bella y pura imagen de su personalidad y su autonomía.» (34)

El proceso de transición desde el sistema político autoritario a un régimen de libertades públicas se produjo lentamente al principio, pero con una dinámica considerable a partir del otoño de 1976. Tras las primeras elecciones libres en cuarenta y un años, se reunieron las Cortes, que tuvieron condición de constituyentes, pues en el período de un año (diciembre 1977 a diciembre 1978) se elaboró, aprobó y promulgó la Constitución Española de 1978.

(34) Véase Díez González, Florentino A: Ei Concejo..., op. cit., p. 581. 
a) El proceso constituyente.

En una Constitución inspirada en la soberanía del pueblo, que declaraba al Estado como social y democrático de Derecho y reconocía la autonomía de las Comunidades territoriales, era normal que el Concejo Abierto también quedase reconocido expresamente en la misma (35).

Pocas modificaciones experimentó la figura local que estudiamos, pues en el proyecto de Constitución presentado en diciembre de 1977 figuraba en último párrafo del artículo 105 en estos términos: «La Ley regulará las condiciones en las que procedan las reuniones en concejo abierto», y en el texto promulgado un año más tarde, será el último párrafo del artículo 140, sustituyendo la voz reuniones por «régimen».

Cuestión que a primera vista pudiese parecer simple, pero no lo era, pues reuniones era un concepto excesivamente generalista que no concretaba o dejaba en el aire la posibilidad de institucionalizar el Concejo Abierto. Por el contrario el concepto «régimen» implica una concreción y sí abre las puertas a la institucionalización.

En los votos particulares al proyecto de Constitución Alianza Popular proponia una redacción alternativa que no mencionaba el Concejo Abierto (36). Sin embargo, la Ponencia admitió el texto del Proyecto en su integridad (37).

En los debates de la Comisión Constitucional del Congreso el tema del Concejo Abierto fue planteado por el diputado Cisneros Laborda, proponiendo un cambio en el texto en los siguientes términos: «Se respetarán los regímenes de Concejo Abierto en los municipios en que funcionen tradicionalmente», que consideraba más acorde con la realidad al tratarse de un régimen municipal alternativo al Ayuntamiento y que de acuerdo con nuestro derecho histórico no convendría generalizarlo, sino solo hacerlo realidad en los lugares que por costumbre funcionase.

A ello se opuso el señor Fraga por considerar que de esta forma el Concejo Abierto quedaba relegado a una especie a extinguir, y no veía la inconveniencia de que un municipio regido por Ayuntamiento pasase a serlo por Concejo Abierto. La solución intermedia la dio el diputado socialista Peces Barba el cual propuso la sustitución del término «las reuniones» por el de «régimen», como finalmente constaría en el texto promulgado; tal concepto permitió abrir el Concejo Abierto a otros municipio, en las condiciones que fijase la

(35) Véase Parejo Alfonso, L.: «Garantia institucional y autonomias locales», IEAL, Madrid, 1981, p. 96.

(36) B.O.C.E. número 44, de 5 de enero de 1978, p. 699. En la Comisión del señor Fraga diría que presentaban el texto alternativo con la salvedad de que no se opondrian a las diversas mociones referentes al Concejo Abierto. D. S. Comisión Constitucional número 88, 14-6-78 p. 3236).

(37) Véase B.O.C.E. número 82, de 17 de abril de 1978, p. 1582. 
ley, y se mantenía la existencia de las que tradicionalmente utilizaban el sistema (38).

Realizada la votación fue aprobado el texto propuesto por Peces Barba por 29 votos a favor, ninguno en contra y tres abstenciones.

En el pleno del Congreso de los Diputados, tras realizar el voto particular que Alianza Popular había presentado a todo el título VIII, y al no existir enmiendas a los artículos 131 a 134, donde se integraba la figura del Concejo Abierto, fueron sometidas a votación y aprobadas por 287 votos a favor, dos en cotra y 13 abstenciones.

En el texto que pasaria al Senado, el Concejo Abierto figuraba al final del artículo 139, y se debatió en la Comisión el día 3 de octubre de 1978.

En tal ocasión el senador don Lorenzo Martín Retortillo propuso una importantísima adición al texto referente al Concejo Abierto, consistente en añadir la siguiente frase: «Así como la función de los barrios.»

Lo argumentaba en función de la vitalidad política que tenían los barrios «y que han de seguir teniendo en el futuro». Diferenciaba el senador los barrios de las grandes aglomeraciones urbanas, donde se ha producido un importantísimo movimiento de participación ciudadana que demandaba cauces y procedimientos para hacerla eficaz, sacudiendo al poder municipal que se había olvidado casi totalmente de la existencia de tales ciudadanos.

Pero también era preciso regular la situación de numerosas aldeas y pequeños núcleos de población que de una u otra forma se integraban alrededor de una cabecera de municipio y donde también los que podríamos llamar Concejos del Alfoz eran marginados y olvidados en la prestación de servicios y en las atenciones, pero no en las obligaciones, por ello proponía la adición de referencia pues constituiría «un apoyo no solo para la defensa de la España concentrada, sino también de la España difuminada a lo largo de nuestro territorio».

Sometido a votación, lamentablemente fue rechazada la propuesta del senador Martín Retortillo por 132 votos en contra, 29 a favor y 10 abstenciones (39).

A partir de este momento el proyecto cumpliria todos los trámites sin modificación alguna, en lo que respecta al Concejo Abierto, y así figuraria en el artículo 140 de la Constitución Española de 1978.

(38) Véase D. S. Comisión Constitucional número 88, 14 de junio de 1978, pp. 3237-3239.

(39) Véase D. S. Senado número 65 , de 3 de octubre de 1978, pp. 3210-3213. 
b) Los proyectos de Ley de Régimen Local.

Después de promulgarse la Constitución, uno de los desafios pendientes en la vida política española era indudablemente la reforma del Régimen local, cuenta sin saldar desde los orígenes del municipio constitucional. Diversas vicisitudes y problemas más graves aún, como el de la articulación de la organización territorial del Estado por medio de las Comunidades Autónomas, dilató la hora de convertir en realidad aquella reforma local.

Tras un intento que no pasó de la redacción de un estudio de anteproyecto en 1978, incluso antes de las primeras elecciones democráticas municipales de 1979, el gobierno de UCD presentó un proyecto de Ley a las Cortes, fruto de los pactos que en la primaveraverano de 1981 habia suscrito con la oposición socialista.

El proyecto recogía la figura del Concejo Abierto dentro del capítulo dedicado a los regímenes municipales especiales, lo que para Díez GoNZÁlez suponía un riesgo para su desarrollo, al presentarse conjuntamente con el Régimen de carta, los pequeños municipios y las Corporaciones Metropolitanas (40).

El proyecto, en su artículo 29 , determinaba que funcionarian en Concejo Abierto los municipios que tuviesen tradicionalmente dicho régimen de gobierno y todos los demás menores de 100 habitantes.

Dispondrian de un alcalde y una Asamblea vecinal formada por todos los electores, en cuanto a su funcionamiento se ajustarían a los usos, costumbres y tradiciones locales, y en su defecto, a la legislación del Estado y las CC.AA.

Sin embargo, el proyecto no hacía referencia a la posibilidad de que las Entidades locales menores accediesen al Régimen de Concejo Abierto, cuando en la práctica funcionan muchas así. Tal omisión que sería corregida posteriormente en la vigente Ley de Régimen Local, la calificaba Díez González de gravísima, no sólo por el olvido de la costumbre, sino por cuestiones funcionales. Por tanto señalaba el ilustre municipalista:

«De ahí que la nueva ley, que se propone, no puede estar ausente de esta realidad y por ello las previsiones que establece para el municipio, en cuanto a dicho régimen, deben hacerse extensivas explicitamente, para la Entidad local menor» (41).

c) La Ley $7 / 1985$.

En la primavera de 1984, se presentó un proyecto de Ley de Régimen Local que se tramitaria integramente hasta su promulgación

(40) Véase Diez González, F. A. El Concejo ..., op. cit. p. 582.

(41) Idem pp. 582-583. 
por un parlamento democrático y verdaderamente representativo, quizá por primera vez en la historia del constitucionalismo español.

No es este el lugar para recordar las ocasiones frustradas en el régimen local, pero sí diremos que desde 1812 ha sido una constante. Tenemos la esperanza de que tal situación no se vuelva a repetir.

El proyecto dedicaba el artículo 28 al Concejo Abierto, dentro de un capítulo titulado «Regimenes Especiales», que reconocía el funcionamiento en Concejo Abierto, de todos los municipios que tradicionalmente dispusieran de tal régimen de gobierno y administración, y además, podían incorporarse aquellos que por razones geográficas, 0 número de habitantes, la gestión de los intereses municipales lo hiciese aconsejable.

En este último caso el trámite para tener Concejo Abierto se iniciaria con la petición de la mayoría de los vecinos, decisión favorable por mayoría de dos tercios del Ayuntamiento y aprobación por la Comunidad Autónoma.

El gobierno y la administración municipal corresponden a un alcalde y una Asamblea vecinal formada por todos los electores. Quedando ajustado su funcionamiento «a los usos, costumbres y tradiciones locales y, en su defecto, a lo establecido en esta Ley y las Leyes de las Comunidades Autónomas sobre régimen local».

Las entidades de ámbito territorial inferior al municipio, se recogían en el artículo 43, siendo competentes las Leyes de régimen local de las Comunidades Autónomas para su regulación, bajo el criterio de «administración descentralizada de núcleos de población separados». No obstante lo expuesto, podía establecerse el régimen de Concejo Abierto para las entidades en que concurriesen las características del artículo 28.1, b), referidas a la localización geográfica o el número de habitantes.

El proyecto iba perfilando los aspectos que se elevarian a definitivos poco tiempo después. Detalle importante fue la determinación fijada en el dictamen de la Ponencia para constituir el Concejo Abierto, en todos los municipios inferiores a 100 habitantes. Iniciado los debates en la Comisión de Administraciones Públicas del Congreso, se presentaron diversas enmiendas al artículo que hacía referencia al Concejo Abierto, siendo discutidas el 22 de octubre de 1984.

La primera enmienda defendida, que era en realidad una nueva redacción del artículo, proponía la supresión de los apartados 2 y 3 del proyecto, quedando redactada en los siguientes términos:

«Los municipios que vienen funcionando en Régimen de Concejo Abierto podrán mantenerlo en sus justos términos y los demás podrán adaptarlo con arreglo a la Ley que se dicte, 
correspondiendo el gobierno y la administración a la asamblea de vecinos y al alcalde, que ostentará la condición de presidente de la asamblea, y a la que se entenderán referidas las facultades reservadas al pleno de los municipios regidos por el Ayuntamiento.»

Interpretaba el representante vasco señor Zubía que el resto de la regulación debía ser competencia de la Comunidad Autónoma. En el mismo sentido se manifestaría el señor Gomis de la minoría catalana.

El Grupo Popular estaba conforme con la redacción de los apartados 2 y 3, pero mantenía una enmienda del señor Vallina que solicitaba para la creación del Concejo Abierto la mayoría absoluta en lugar de los dos tercios. Igualmente mantenian la necesidad de un informe previo de la Diputación Provincial para la creación del Concejo Abierto (42).

La intervención más extensa fue la presentada por el señor Núñez del Grupo Centrista, cuya primitiva sugerencia de 100 habitantes habia sido recogida por la Ponencia y que pedia dar mayor realce al tema por la posibilidad de que los propios municipios en régimen de Concejo Abierto... «puedan cristalizar, dentro de esa regulación que se va a derivar de esta ley, todas las apetencias autonómicas que puedan pretender respecto del municipio mayor, en cuyo marco geográfico están incluidas.»

No fue admitida ninguna enmienda quedando aprobado el texto de la Ponencia por 20 votos a favor y 12 abstenciones (43).

Posteriormente el proyecto de Ley Reguladora de las Bases de Régimen Local pasó a discusión en el pleno del Congreso debatiéndose el artículo referente al Concejo Abierto en la sesión del día 15 de noviembre de 1984. Mantendría su postura el diputado catalán y parcialmente el señor Vallina de Coalición Popular, la cual sería aceptada en el sentido de que «el gobierno y la administración municipal corresponden al Ayuntamiento integrado por el alcalde y los concejales, salvo en los casos de Concejo Abierto»; ésta última frase era la admitida por el Pleno. Finalmente, puesto a votación el artículo se aprobó por 165 votos a favor, seis en contra y 89 abstenciones (44).

El siguiente trámite del proyecto, fue su paso al Senado para ser estudiado en la Comisión de Autonomías y Organización y Administración Territorial, y ser debatido el articulado referente al Concejo Abierto en la Sesión plenaria del día 20 de febrero de 1985 , que también iniciaba los debates. Tras las enmiendas a la totalidad,

(42) D.S.C. Comisiones, núm. 225, 22 de octubre de 1984, pp. 7.057.

(43) Idem, p. 7.509.

(44) Véase D.S.C. Pleno núm. 166, de 15 de noviembre de 1984, p. 7.493. 
rechazadas por 132 votos frente a dos en contra y 48 abstenciones, se discutieron por títulos, correspondiendo al título II, artículos 11 al 30 , el último periodo de la sesión.

El senador Alvarez Cascos Fernandez insistió en la necesidad de que en la constitución del Concejo Abierto informase preceptivamente la Diputación Provincial; excepto tal indicación, que no prosperó, no hubo más referencias al tema, siendo aprobado por 132 votos a favor, 28 en contra y una abstención. Al haberse producido modificaciones en el Senado, el proyecto de Ley pasó a la Comisión Mixta Senado-Congreso que aprobó definitivamente el proyecto, como Ley $7 / 1985$, de 2 de abril, publicada en el $B O E$ núm. 80 , de 3 de abril.

Después de la prolija exposición que hemos realizado parece recomendable analizar con cierto detalle todos los preceptos relativos al régimen de Concejo Abierto, comenzando por el artículo 19 referente a la organización, por el que el gobierno y la administración municipal corresponden al Ayuntamiento «salvo en aquellos municipios que funcionen en Régimen de Concejo Abierto». En consecuencia la distinción es tajante: Hay municipios constituidos por Ayuntamientos y por Concejos Abiertos. No hay posibilidad de error ni de confusión. Tal distinción será más complicada en aquellas Entidades locales menores que funcionen en régimen de Concejo Abierto sin ser municipios, pero el legislador paulatinamente irá resolviendo el problema (45).

El texto definitivo como hemos visto sólo tenía la incorporación respecto al proyecto del número de habitantes para constituirse en Concejo Abierto. La Ley ha determinado que todos los municipios españoles con menos de 100 habitantes tendrán este sistema de gobierno municipal, además de todos los que tradicionalmente lo tuviesen o los que cumplan los trámites para conseguirlo.

En el artículo 49.2, b), se recoge en los mismos términos del proyecto la posibilidad de establecerse Concejo Abierto en las Entidades locales menores. Ahora bien, en este sentido y previsto por otra norma de rango importante (el Real Decreto Legislativo 781/1986, de 18 de abril), figuran los artículos 39,41 referente a las Entidades locales menores, que hacen mención a la Asamblea vecinal o Junta vecinal, que no define, pero indudablemente pueden inducir a error al identificarla con la Asamblea vecinal prevista en el artículo 29.3 de la Ley $7 / 1985$, la cual está formada por todos los electores (46).

(45) Véase Parejo Alfonso, L.: Garantia..., op. cit.

(46) Véase Sánchez Santiago, J. L.: «El Sistema de Concejo Abierto en las Entidades de ámbito territorial inferior al municipal». (En «El Concejo Abierto»). Madrid. IEAL. 1987, pp. 46-70. 
La articulación amplia del Concejo Abierto ha tenido lugar con la promulgación del Reglamento de Organización, Funcionamiento y Régimen Jurídico de las Entidades Locales de 28 de noviembre de 1987, que además de establecer el Concejo Abierto en su artículo $2 .^{\circ}$ como forma de gobierno y administración municipal, prevé que estas funciones se ejercerán por «una Asamblea integrada por todos los lectores existentes en el municipio y por el alcalde elegido directamente por ellos».

Para la organización del municipio en Concejo Abierto, dispone el artículo 54.1 que las atribuciones de la Asamblea y del alcalde «se regirán por los usos, costumbres y tradiciones locales y, en su defecto, por la Ley $7 / 1985$, de 2 de abril, por las Leyes de las Comunidades Autónomas sobre Régimen Local y por las normas de las secciones segunda y cuarta de este capítulo", o sea de todas las especificaciones referentes al alcalde (artículos 40 a 45) y al Pleno (artículos 49-51) de los Ayuntamientos donde se detallan los procedimientos de su actuación, lo dispuesto en sus competencias y obligaciones.

Según el apartado 2 del referido artículo 54, el alcalde podrá designar tenientes de alcalde, hasta un máximo de tres entre los electores del municipio, los cuales tendrán las mismas funciones y atribuciones que sus homónimos de los Ayuntamientos. Llama la atención la fórmula de designación directa por el alcalde, frente a la electiva prevista en otras normas del pasado sobre todo el Estatuto Municipal o la Ley Municipal de 1935, aunque se puede explicar por la condición de concejal de cada uno de los electores.

Las normas de funcionamiento de las Asambleas vecinales en régimen de Concejo Abierto previstas en el artículo 111 son muy completas y válidas. En principio se prevé su ajuste a los usos, costumbres y tradiciones locales, a la Ley 7 , a las de las CC.AA. y al capítulo I del título IV, referente al funcionamiento del pleno, donde se determinan y regulan los requisitos para la celebración de las sesiones los debates, las votaciones, el control por el pleno de la actuación de los demás órganos y de las actas. El párrafo $2 .^{\circ}$ dice textualmente:

«Las Asambleas vecinales se reunirán donde lo tengan por costumbre, celebrarán sesión ordinaria como mínimo una vez al trimestre en día festivo, y serán convocadas a toque de campana, por pregón, por anuncio o por cualquier otro medio de uso tradicional en el lugar.»

Para que la Asamblea sea válida, tiene que asistir una tercera parte de los vecinos presentes o representados que a ello tengan derecho, no pudiendo nunca los presentes ser menos de tres. En la Asamblea deberá estar siempre presente el presidente y el secretario o quienes 
legalmente les sustituyan, y los acuerdos tendrán que tomarse por mayoria de votos (47).

La cuestión de los representados plantea una perspectiva nueva, pues no olvidemos que en los pequeños municipios hay vecinos ausentes que vuelven a sus casas en épocas concretas, unos con más frecuencia que otros. El caso es que se ha regulado tal situación, documento privado con firma notarialmente legitimada o poder otorgado ante el secretario de la Entidad local. Esta fórmula no permite que ningún vecino asuma la representación de más de un tercio de la Asamblea vecinal. En cuanto a las normas que regulan las Entidades locales menores, cuyo órgano de gobierno denomina el Reglamento Junta Vecinal, deshaciendo los equivocos del Real Decreto Legislativo, citado antes, disponen la constitución y régimen de sesiones, «sin perjuicio de los casos en que proceda el régimen de Concejo Abierto», según señala el artículo 144.

Con ello se cierra una cuestión que se ha planteado anteriormente, subsanándose la omisión que señalaba DíEZ GonZÁlez en 1982.

Con esto se culmina un antiguo deseo, plasmado hace casi un śiglo, y se realiza un acto de justicia con una institución que algunos ignoraban y otros vituperaban. Ya hemos demostrado que está viva y no creemos que se encuentre en lucha con el concepto urbano. La crisis, la elevación del nivel económico y social, los planteamientos ecológicos suponen un freno a la emigración, y en algunos casos el retorno. De acuerdo que la mayor parte de la población se concentrará en las urbes, pero esa ha sido una constante en la humanidad. El caso es que la aldea seguirá viviendo y con ella el Concejo Abierto, consagrado en la legislación española en el momento actual en más de 700 municipios.

(47) Véase Cosculluela Montaner, L.: "El Concejo Abierto», Madrid, REALA núm. 234, abril-junio 1987, pp. 199-224. Sin duda el estudio juridico más completo sobre la figura del Concejo Abierto. Díez González, F. A.: «Funcionamiento de los Municipios y Entidades de Concejo Abierto» (En El Concejo Abierto) Madrid. 1987, pp. 92-113. 
REALA-1988, núm. 237. ORDUÑA REBOLLO, ENRIQUE. LA EVOLUCION DEL CONCEJO ABIERTO ...

REALA-1988, núm. 237. ORDUÑA REBOLLO, ENRIQUE. LA EVOLUCION DEL CONCEJO ABIERTO ... 